low association of ADHD and BPD, probably only 5\%, and cautions against the risk of an overdiagnosis and treatment of $\mathrm{ADHD}$ as $\mathrm{BPD}$, or as a comorbid disorder.

Mania with pervasive developmental disorder is reported in 14 children, representing $21 \%$ of a group of PDD subjects, in a study at the Massachusetts General Hospital (Wozniak J, Biederman J, Faraone SV, et al. I Am Acad Child Adolesc Psychiatry November 1997;36:1552-1559). According to the authors, comorbid mania among patients with PPD may be more common than previously thought.

Symptoms of mania can include an abnormal and persistently elevated, expansive, or irritable mood, hyperactivity, distractibility, inappropriate cheerfulness, excessive talking, and silliness, sleeplessness, agitation, and aggressive outbursts. Adults with manic episodes also engage in inappropriate business ventures, unrestrained buying sprees, and irresponsible credit card debt.

Aggression in boys with ADHD was associated with parent aggressive behavior and lower 5-HT, central serotonergic function in a study of 41 boys at Queens College, Flushing, NY. (Halperin JM, Newcorn JH, Kopstein I, et al. Serotonin, aggression, and parental psychopathology in children with attention-deficit hyperactivity disorder. I Am Acad Child Adolesc Psychiatry Oct 1997;36:1391-1398). Serotonergic function was assessed by the prolactin response to fenfluramine challenge.

\title{
METHYLPHENIDATE FOR ADHD IN PRESCHOOLERS
}

The effectiveness of methylphenidate (MPH), 0.3 and $0.5 \mathrm{mg} / \mathrm{kg} 2 \mathrm{x}$ daily, in the treatment of 31 children, aged 4 to 6 years, with attention-deficit hyperactivity disorder (ADHD) was investigated by a double-blind, placebocontrolled study at the University of Ottawa, Canada. Comorbid oppositional defiant disorder and conduct disorder were present in $84 \%$ and $19 \%$, respectively. While on MPH compared to placebo, significant improvements were obtained on a cognitive measure (number of correct responses on Gordon Vigilance Task), the parent ratings of the child's behavior, and tasks measuring ability to stick with a paper-and-pencil assignment. Parents' ratings were most sensitive. A positive response to MPH on at least one of the measures of attention was obtained in $90 \%$ of patients. Improved performance during MPH was also noted in measures of impulsivity-hyperactivity and conduct. No changes were observed in the childs' compliance with parental everyday requests. Side effects, stomachaches, headaches, anxiety, and sadness, increased in frequency and severity with the higher dosage of MPH. (Musten LM, Firestone P, Pisterman S, Bennett S, Mercer J. Effects of methylphenidate on preschool children with ADHD: cognitive and behavioral functions. IAm Acad Child Adolesc Psychiatry Oct 1997;36:1407-1415). (Reprints: Dr Philip Firestone, Departments of Psychology and Psychiatry, University of Ottawa, 120 University Private, Ottawa, Ontario, Canada K1N 6N5).

COMMENT. Methylphenidate may improve attention and parent-rated behavior of preschool children with ADHD, and comorbidity with oppositional defiant disorder is not a contraindication to its use in younger children. The positive effects of MPH in preschoolers parallels the benefits noted in older children, and side effects are similar and dose related.

\section{NEUROLOGICAL SOFT SIGNS AND PSYCHIATRIC SYMPTOMS}

The association between neurological soft signs, measured by the 